Document downloaded from:

http://hdl.handle.net/10251/122886

This paper must be cited as:

Serrano, J.; Navarro, R.; García-Cuevas González, LM.; Inhestern, LB. (2018).

Turbocharger turbine rotor tip leakage loss and mass flow model valid up to extreme offdesign conditions with high blade to jet speed ratio. Energy. 147:1299-1310.

https://doi.org/10.1016/j.energy.2018.01.083

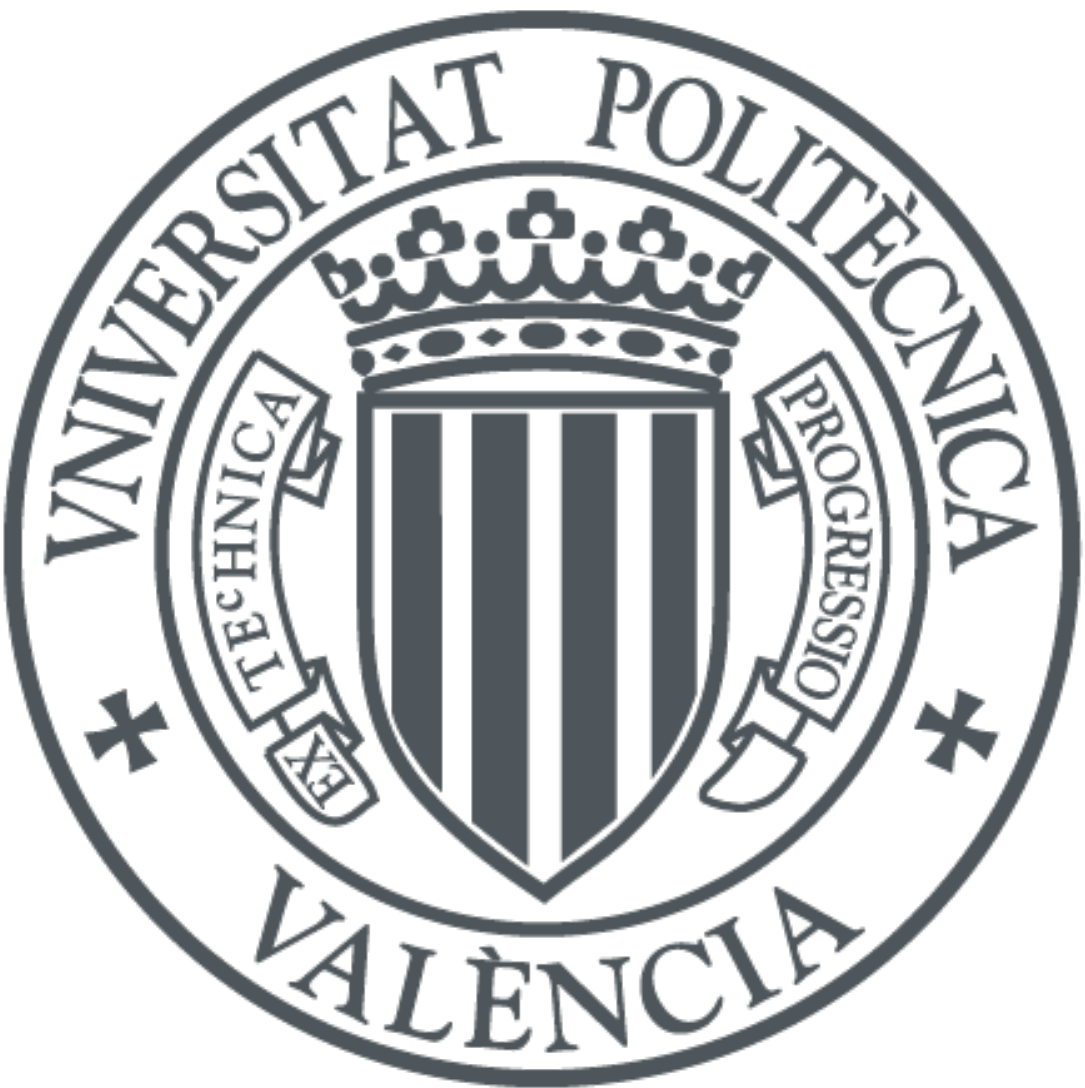

The final publication is available at

https://doi.org/10.1016/j.energy.2018.01.083

Copyright Elsevier

Additional Information 


\section{NOTICE:}

This is the author's version of a work that was accepted for publication at Energy. Changes resulting from the publishing process, such as peer review, editing, corrections, structural formatting, and other quality control mechanisms may not be reflected in this document. Changes may have been made to this work since it was submitted for publication. A definitive version was subsequently published as:

J. R. Serrano, R. Navarro, L. M. García-Cuevas, L. B. Inhestern, Turbocharger turbine rotor tip leakage loss and mass flow model valid up to extreme off-design conditions with high blade to jet speed ratio, Energy 147 (2018) 1299 - 1310. doi:https://doi.org/10.1016/j.energy.2018.01. 083 


\title{
Turbocharger turbine rotor tip leakage loss and mass flow model valid up to extreme off-design conditions with high blade to jet speed ratio
}

\author{
José Ramón Serrano ${ }^{\mathrm{a}}$, Roberto Navarro ${ }^{\mathrm{a}}$, Luis Miguel García-Cuevas ${ }^{\mathrm{a}, *}$, \\ Lukas Benjamin Inhesterna \\ ${ }^{a}$ CMT-Motores Térmicos, Universitat Politècnica de València, Valencia 46022, Spain.
}

\begin{abstract}
Due to the power consumption restriction of the turbocharger compressor, common turbine maps are rather narrow. To extrapolate them, reliable physical submodels are needed that are valid for broad ranges. Plenty of research has been done referring to tip leakage losses in axial and traditional radial turbomachinery. However, less effort has been put into the tip leakage analysis of radial turbocharger turbines, whose characteristics including high rotational speed and geometry are rather different. Commonly developed tip leakage loss models in radial turbines are mainly based on correlations with the rotational speed, while in axial turbomachinery they are mainly based on blade loading assumptions. Wide range computational fluid dynamics (CFD) data of a medium sized automotive turbine have been used to analyze tip leakage mass flow under extremely diverse running conditions. To be able to fit a model in a broad range of the map, blade loading and rotational speed have to be considered. A novel tip clearance model has been derived from the Navier Stokes Equations. The model owns a dependency on the rotational speed and the blade loading. With this approach CFD data have been fitted in a very good quality to model the tip leakage mass flow rate and tip leakage losses.
\end{abstract}

Keywords: Radial turbine model, Tip leakage, Off-design, High BSR, CFD, Wide map

\footnotetext{
*Corresponding author. Tel: +34963877659; fax: +34963877659

Email address: luiga12@mot.upv.es (Luis Miguel García-Cuevas)

$U R L$ : www.cmt.upv.es (Luis Miguel García-Cuevas)
} 


\section{Introduction}

Rising urbanization, mobilization and advancing government restrictions for real driving cycles (as in [1]) shift the engine designers focus towards the conditions of urban driving. At the same time turbocharging technologies are gaining more and more importance in gasoline engines. Thus, conditions where turbochargers encounter highly transient flow partly working under high and partly working under low mass flow (and expansion ratio) are of high interest [2]. For a successful matching of turbocharger and engine, wide turbine maps are needed but rarely available. The restriction of the power consuming compressor also constrains the measurable range of the turbocharger turbine. Advanced measurement procedures using an electrical brake instead of the compressor wheel have been presented by authors like Romagnoli and Martinez-Botas [3], Bellis et al. [4] and Smiljanovski et al. [5]. Later, Terdich [6] was able to maintain the turbocharger speed at low turbine power with an electrically assisted turbocharger. Salameh et al. [7] used a mirrored compressor as a second turbine for powering the turbocharger shaft while the turbine is operating at high blade speed ratio (BSR) conditions. Finally, an industrial applicable measurement technique has been presented by Serrano et al. [8] and deepened in Serrano et al. [9]. However, these measurement techniques are not common practice yet. Nevertheless, wide maps are particularly needed to feed them to one dimensional engine simulation models (Payri et al. [10], Romagnoli and Martinez-Botas [3] and Zhu et al. [11]) and to predict engine matching. Galindo et al. [2] and Aymanns et al. [12] have shown the need of extended map regions up to almost zero turbine torque, since these operating conditions are covered by typical engine pulsating flow. To obtain wide maps, it has become common practice to use physically based one dimensional turbine map extrapolation models [3, 13, 14]. Extrapolation models get fitted by available data from narrow maps and apply the fitted physics on unmeasured regions. These kind of models usually rely on physically based loss sub-models as passage, incidence, or tip clearance loss models. Although a lot of research has been done in this area, available extrapolation models mostly need different sets of fitting coefficients to fit data of one variable geometry turbocharger (VGT) turbine at changed stator blade angles. Hence, the physics of wide maps can not be covered by one model. To increase the physical reliability and thus 
the extrapolation stability loss models are needed which can be valid for the whole wide map data with one set of coefficients.

According to Dambach et al. [15] the dragged tip leakage flow should not be neglected in the radial turbine observation. At off-design conditions with low mass flow and low blade loading the dragged flow through the tip clearance is expected to play an even bigger role as pointed out by Deng et al. [16]. This role could be more extended by the typically high turbocharger rotational speeds. Thus, the tip loss model can be considered as very important to achieve good extrapolation results towards off-design conditions.

Common tip clearance loss correlations are based on the calculation of the kinetic energy passing through the tip gap as it has been done by researchers such as Yaras and Sjolander [17] for axial and by Baines [18] for radial turbines. Further observing the available literature mentioning tip clearance loss models in turbines, different strategies can be identified.

Authors like Yaras and Sjolander [17] modeled the tip clearance flow in axial turbines depending on the blade loading relying on discharged flow. In radial turbomachinery it has been modeled mainly depending on the rotational speed by Spraker [19] and further by Baines [18] applying the observation of different flow patterns in different zones by Dambach et al. [15]. Also empirical approximations have been introduced by Wallace [20] and later generalized by Kammeyer et al. [21]. Although much research has been done in the field of turbine tip leakage modeling yet, the need of fitting to broad range data and later extrapolation towards extreme off-design condition requires a novel model which can estimate losses at different rotational speeds and loadings. Furthermore, turbocharger turbines are operating under very high rotational speeds and own different geometrical properties. No analysis of turbocharger turbine tip leakage flow in this wide range of data has been found in the literature. This paper presents a tip leakage analysis based on the validated wide range CFD data presented by Serrano et al. [22] as well as a novel tip leakage loss and leakage mass flow model to allow consistent data fitting and to extrapolate the data reliably.

First, simulation results are presented and analyzed. Second, the tip leakage model has been developed from the Navier Stokes Equation in a rotational reference frame. Third, the model data has been discussed and validated with the CFD data. Finally, conclusions are presented and potentially future work has been proposed. 


\section{Tip Leakage Flow Characterization}

For characterizing the tip leakage flow in a wide range of operating conditions numerical fluid dynamics have been used. The object of the analysis has been a medium sized automotive radial turbocharger turbine with variable stator vanes. The rotor is shown in Figure 1 and has the geometrical properties presented in Table 1. Tip clearance dimensions considered in Table 1 correspond to $C A D$-like conditions. Modification of the tip profile due to the impeller thermal and rotational deformation (see Galindo et al. [23]) is therefore neglected in this work.

\begin{tabular}{ll}
\hline \hline \multicolumn{2}{c}{ Stator } \\
\hline Blade number & 11 \\
Blade angle $\alpha$ & $72.95^{\circ}(30 \%), 62.95^{\circ}$ \\
(VGT opening) & $(60 \%), 53.45^{\circ}(80 \%)$ \\
\hline \multicolumn{2}{c}{ Rotor } \\
\hline Blade number & 9 \\
Inlet diameter & $41 \mathrm{~mm}$ \\
Outlet diameter & $38 \mathrm{~mm}$ \\
Outlet blade angle & $59^{\circ}$ \\
Inlet tip clearance $\Delta r_{\text {tip,in }}$ & $0.36 \mathrm{~mm}$ \\
Outlet tip clearance $\Delta r_{\text {tip,out }}$ & $0.4 \mathrm{~mm}$ \\
Axial tip clearance & $13 \mathrm{~mm}$ \\
length $\left(l_{\text {tip,ax. }}\right)$ & \\
Leading edge thickness $\Delta \theta$ & $0.0195 \mathrm{rad}(0.4 \mathrm{~mm})$ \\
\hline \hline
\end{tabular}

Table 1: Turbine geometry characteristics.

Overall, results from 122 simulations of three different VGT positions $(30 \%, 60 \%, 80 \%)$ and three different rotational speeds $\left(1710 \mathrm{rpm} / \mathrm{K}^{0.5}, 3890 \mathrm{rpm} / \mathrm{K}^{0.5}\right.$, $6715 \mathrm{rpm} / \mathrm{K}^{0.5}$ ) have been obtained. Thus 9 speedlines, starting from design conditions down to even negative power output, have been employed as it can be seen in Figure 2.

Steady RANS simulations have been solved by the segregated solver of Star-CCM+ 12.04. The turbulence has been modeled by the k- $\omega$ SST model [24], which is considered as a good choice for radial turbocharger simulations $[25,26]$. A polyhedral mesh with prism layers at the wall and an overall wall $y^{+}$value of around 1 has been utilized. The CFD model was validated in 


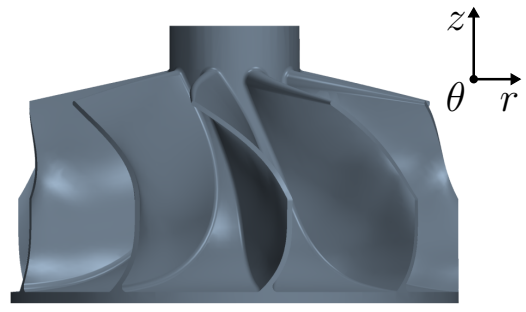

Figure 1: Turbine rotor geometry.

detail against global parameters of experimental extended map results and overall mesh convergence was stated for $3890 \mathrm{rpm} / \mathrm{K}^{0.5}$ in Serrano et al. [22]. To prove the cell density in the tip gap is adequate, the cell amount in the rotor tip gap has been doubled without an important change in the tip leakage mass flow rate at higher and lower pressure ratio. The mass flow map and power outputs of the simulated running points are shown together with experimental data in Figure 2. Since there is a significant uncertainty when adjusting the VGT opening in the experiment, the replication of the tested position in the CFD model has to be achieved by moving the model stator blades stepwise, as it has been discussed by Galindo et al. [27]. The VGT opening was varied until the mass flow rate of the points at $3890 \mathrm{rpm} / \mathrm{K}^{0.5}$ and with highest expansion ratio are obtained as explained in Serrano et al. [22]. Therefore, numerical predictions for this speed show very good agreement with experimental results. The experimental measurements of other speeds were obtained during different measurement sessions, so that the experimental VGT position differs slightly for different speeds. The VGT position of the numerical model has not been further adjusted for the remaining speeds to allow a consistent CFD database. However, Figure 2 shows that the qualitative behavior of reduced mass flow and turbine power has been reproduced with an overall good quality for the highest and lowest simulated speeds.

In the following, the nomenclature for positive and negative tip leakage flow has been used according to Figure 3. Relative positive flow is directed towards the blade suction surface (SS) and relative negative flow towards the blade pressure surface (PS). Although positive and negative mass flows are provoked by different physical effects, both are considered as loss sources. Thus, mass flow ratios into both directions are summed to highlight the overall impact of the existing tip gap. 


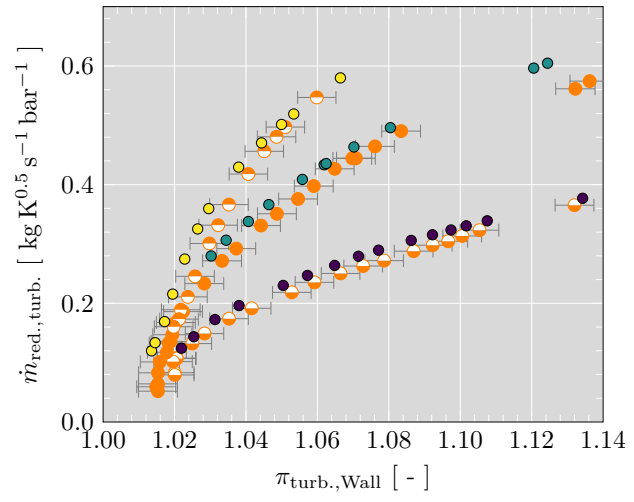

(a) $\dot{m}_{\text {red. }}$ at $1710 \mathrm{rpm} / \mathrm{K}^{0.5}$.

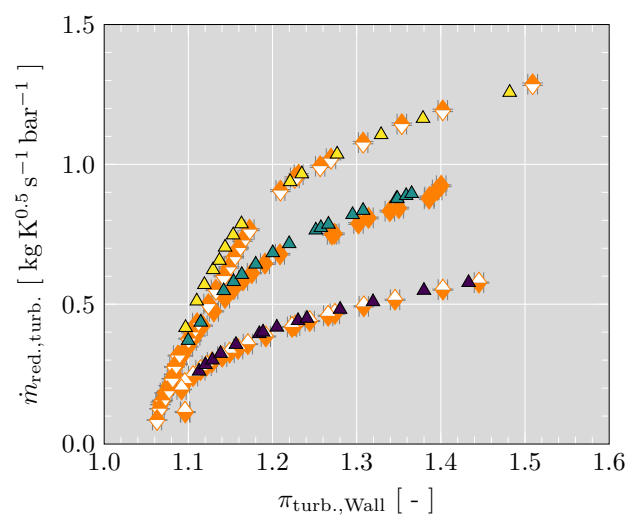

(c) $\dot{m}_{\text {red. }}$ at $3890 \mathrm{rpm} / \mathrm{K}^{0.5}$.

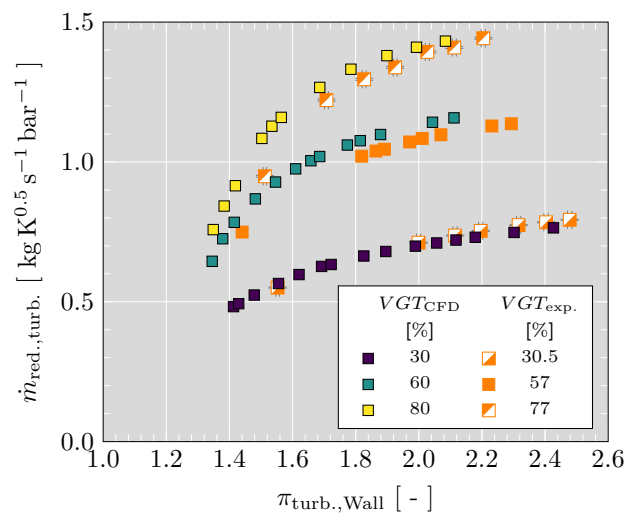

(e) $\dot{m}_{r e d}$ at $6715 \mathrm{rpm} / \mathrm{K}^{0.5}$.

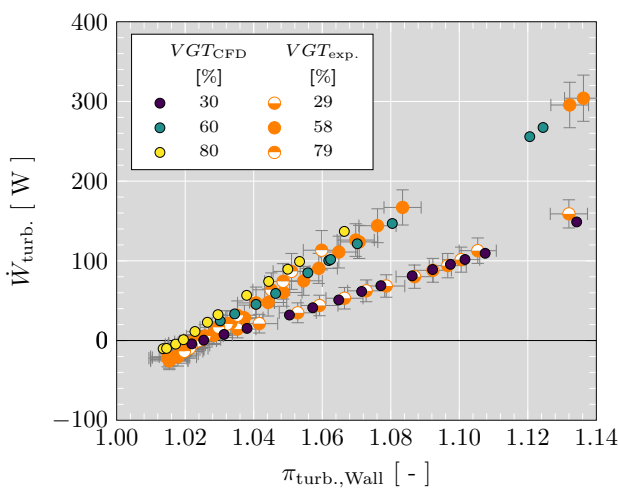

(b) $\dot{W}_{\text {turb. }}$ at $1710 \mathrm{rpm} / \mathrm{K}^{0.5}$.

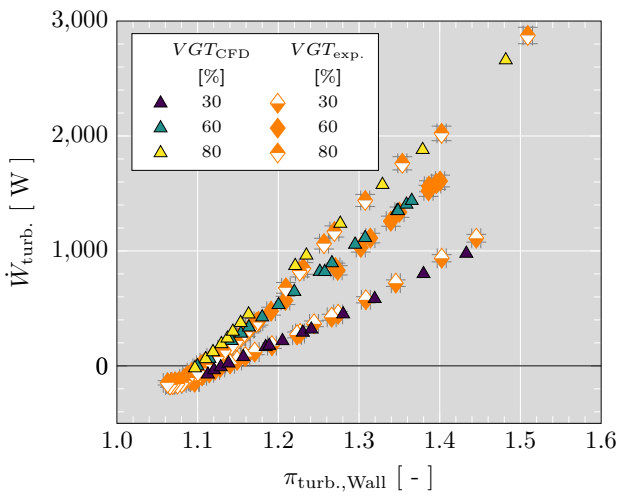

(d) $\dot{W}_{\text {turb. }}$ at $3890 \mathrm{rpm} / \mathrm{K}^{0.5}$.

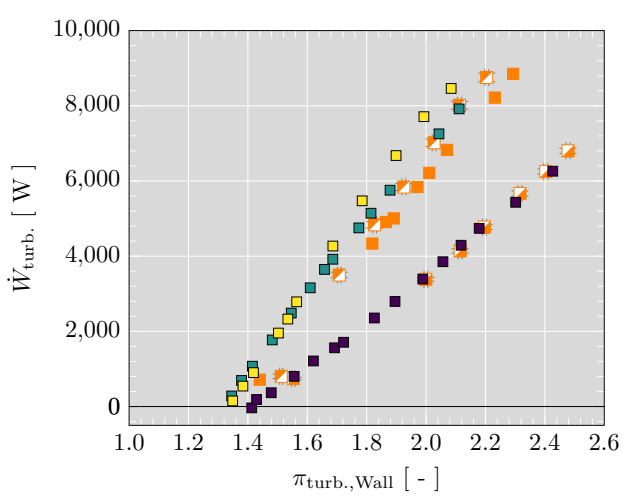

(f) $\dot{W}_{\text {turb. }}$ at $6715 \mathrm{rpm} / \mathrm{K}^{0.5}$.

Figure 2: Reduced mass flow rate (left) and turbine power (right) for different reduced isospeeds. 


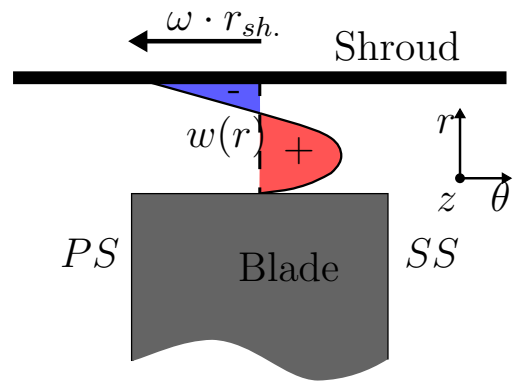

Figure 3: Tip leakage flow definition in rotating reference frame

$$
\begin{aligned}
\frac{\dot{m}_{\mathrm{tip},+}}{\dot{m}_{\mathrm{turb} .}} & =\frac{\int \rho \cdot w_{\perp, \mathrm{tip},+} \mathrm{d} A_{+}}{\dot{m}_{\mathrm{turb} .}} \\
\frac{\dot{m}_{\mathrm{tip},-}}{\dot{m}_{\mathrm{turb} .}} & =\frac{\left|\int \rho \cdot w_{\perp, \mathrm{tip},-} \mathrm{d} A_{-}\right|}{\dot{m}_{\mathrm{turb}}} \\
\frac{\dot{m}_{\mathrm{tip}}}{\dot{m}_{\mathrm{turb} .}} & =\frac{\dot{m}_{\mathrm{tip},+}}{\dot{m}_{\mathrm{turb}}}+\frac{\dot{m}_{\mathrm{tip},-}}{\dot{m}_{\mathrm{turb}}}
\end{aligned}
$$

The integrals have been taken over the tip gap along the edge at the SS of the blade. Figure 4 shows the relative mass flow passing the tip gap with the definition of Equation 3 at all simulated running points. Apparently, the overall leakage flow ratio is higher at closer VGT openings. It can be seen that between $5 \%$ and $9 \%$ of the net mass flow passes the tip gap at higher simulated pressure ratios for different VGT openings at $1710 \mathrm{rpm} / \mathrm{K}^{0.5}$. This variation diminishes with increasing speed. At the highest speed and high pressure ratios, the leakage flow ratio ranges between $6 \%$ and $8 \%$. Reducing the pressure ratio, the leaking mass flow ratio decreases first for $1710 \mathrm{rpm} / \mathrm{K}^{0.5}$ and $3890 \mathrm{rpm} / \mathrm{K}^{0.5}$ while it rises slightly for $6715 \mathrm{rpm} / \mathrm{K}^{0.5}$. Going to very low pressure ratios the tip leakage ratio shows a sharp increase. This confirms the importance of the tip leakage flow and losses at extreme off-design conditions.

As mentioned before, the tip leakage flow of traditional radial turbines can be distinguished between certain zones of positive and negative (due to higher circumferential speed at the rotor inlet) mass flow over the tip gap along the chord length (Dambach et al. [15]). Following, mass flows in both directions have been analyzed in detail for the observed radial turbine. In Figure 5 the relative tip leakage velocity $w_{\perp, t i p}$ is shown at all three rotational speeds in the running points of highest and lowest simulated expansion ratio 


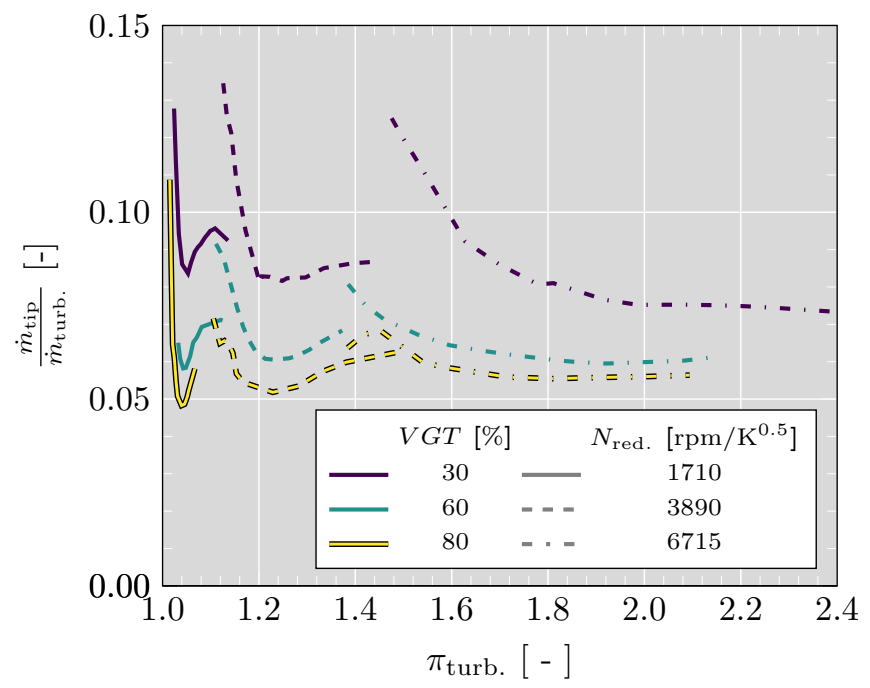

Figure 4: Overall relative mass flow fraction trough the rotor tip gap.

for $60 \%$ VGT opening. It can be seen that the extension of regions with positive and negative flow changes significantly from high pressure ratio points (Figure 5 (a), (b), (c)) to low pressure ratio points (Figure 5 (d), (e), (f)). The extension of the positive flow dominates clearly the one of the negative flow. The later, induced by shroud friction, is negligible at higher expansion ratios over the majority of the chord length. An increase of positive leakage flow over the tip leakage is visible when the rotational speed and thus the blade loading rises. At the same time, the positive tip leakage velocity diminishes in the inlet region of the rotor with increasing rotational speed. This might be affected by the higher negative incidence at faster wheel rotation as it can be seen in Figure 6. Nevertheless, Figure 7 shows that the negative incidence is not high enough to cause a swapping of the local pressure gradient at $6715 \mathrm{rpm} / \mathrm{K}^{0.5}$ close to the tip. Another reason for increasing negative flow can be the high negative incidence inlet flow that owns high relative inlet swirl and inertia in contrariwise direction. Also, the impact of shroud friction rises with increasing rotational speed and leads to more negative flow.

At reduced expansion ratio (Figure 5 (d), (e), (f)) the tip leakage flow behavior changes over the tip length. Two zones can be clearly distinguished. First, one zone at the outlet section, where the positive velocity flow still dominates. Although the shroud friction gains importance in this zone, the impact is rather low here. Second, one zone at the inlet section of the turbine 


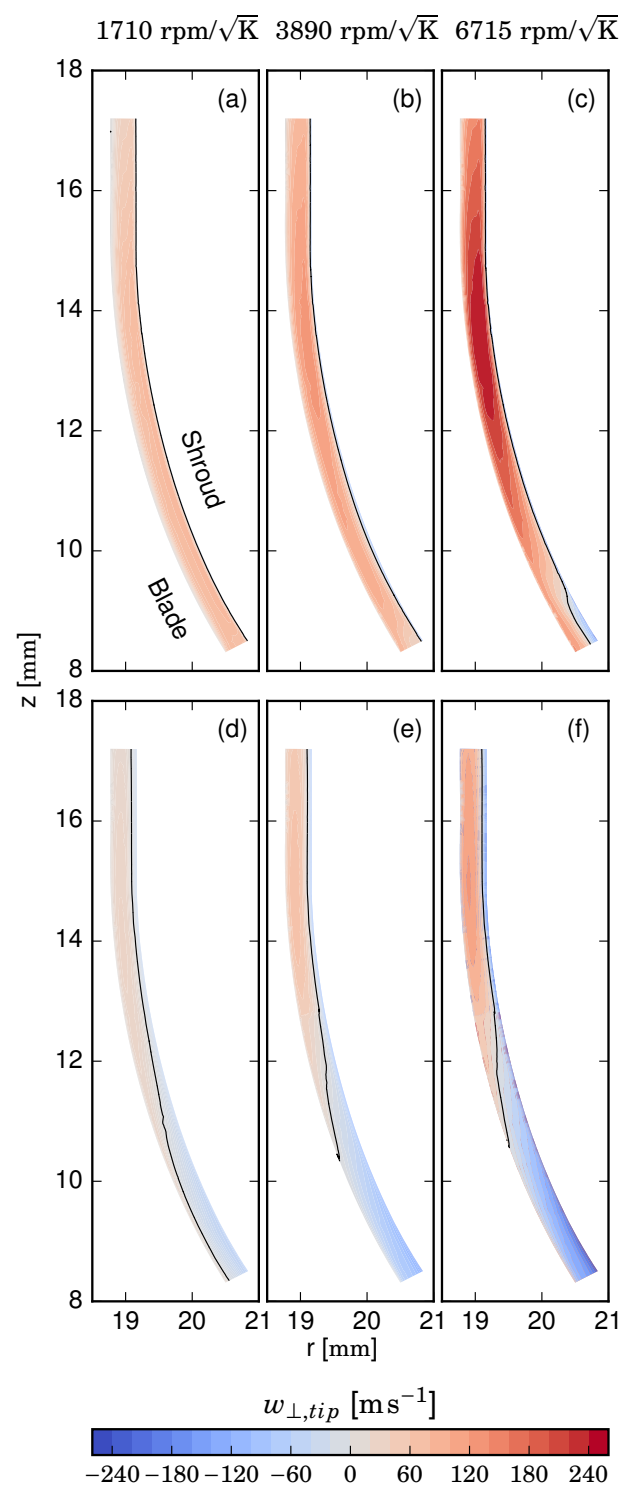

Figure 5: Tip leakage flow along the suction side edge at highest simulated $\pi_{\text {turb. }}: 1.12$ in (a), 1.37 in (b), 2.11 in (c) and at lowest simulated $\pi_{\text {turb. }}: 1.03$ in (d), 1.10 in (e), 1.35 in (f) with $60 \%$ VGT opening; Solid black line corresponds to $w=0$. 
wheel, where the negative leakage flow dominates. However this characterization is similar to the one made by Dambach et al. [15], the origin of the negative flow in the inlet region is different. High negative incidence leads to flow separation at the leading edge and thus to a swap of the pressure potential between suction and pressure side as it can be seen in Figure 8. Furthermore, the negative incidence implies a high negative tangential ve-

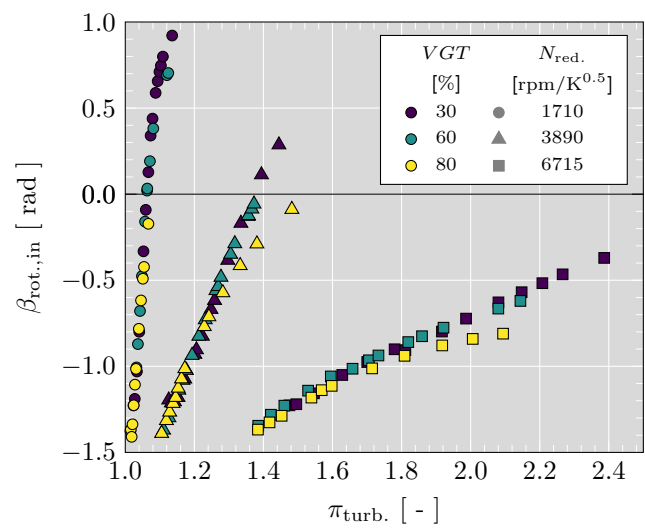

Figure 6: Rotor inlet angle in rotating reference frame.

locity component $w_{\theta}$ as shown in Figure 6 , which benefits the negative leakage mass flow.

The exclusive mass flow ratios of both contrariwise leakage streams according to Equation 1 and Equation 2 have been plotted in Figure 9. The positive mass flow ratio in Figure 9 (a) has an overall declining trend with decreasing pressure ratio $\pi_{\text {turb. }}$. However, at rather low pressure ratios some curves experience a rise for a short period. The reason for this sudden rise could be the restriction of the outlet cross section due to back flow into the rotor as it has been described in Serrano et al. [22]. This way the positive passage flow consists of a higher mass flow than the net mass flow. At the same time the blade might become higher loaded at higher span due to the restricted flow area at the hub. The negative mass flow ratio in Figure 9 (b) is continuously rising for all speedlines by decreasing pressure ratio. While the negative mass flow is related to the rotational speed, the positive mass flow is rather related to the blade loading at the tip. 


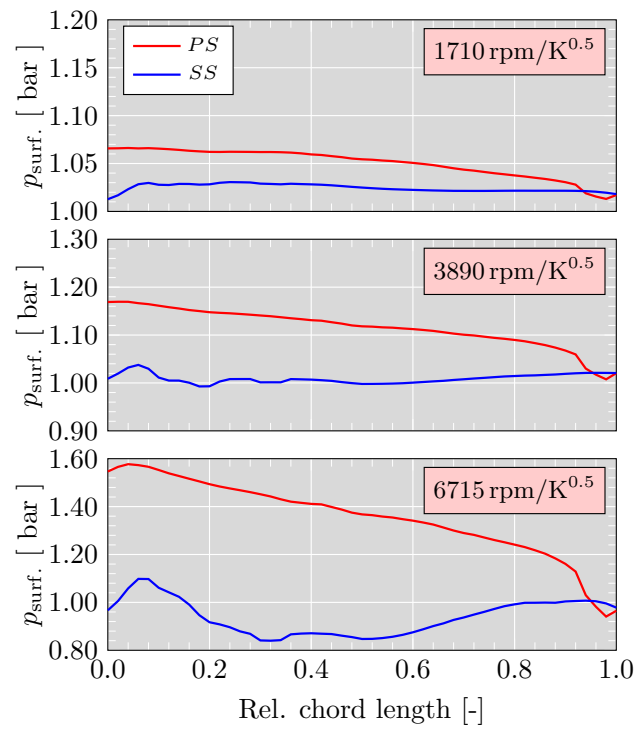

Figure 7: Surface pressure profiles at $95 \%$ span at highest simulated $\pi_{\text {turb. }}$ for each speed with $60 \%$ VGT opening $\left(\pi_{\text {turb. }}: 1.12\right.$ at $1710 \mathrm{rpm} / \mathrm{K}^{0.5}, 1.37$ at $3890 \mathrm{rpm} / \mathrm{K}^{0.5}, 2.11$ at $\left.6715 \mathrm{rpm} / \mathrm{K}^{0.5}\right)$.

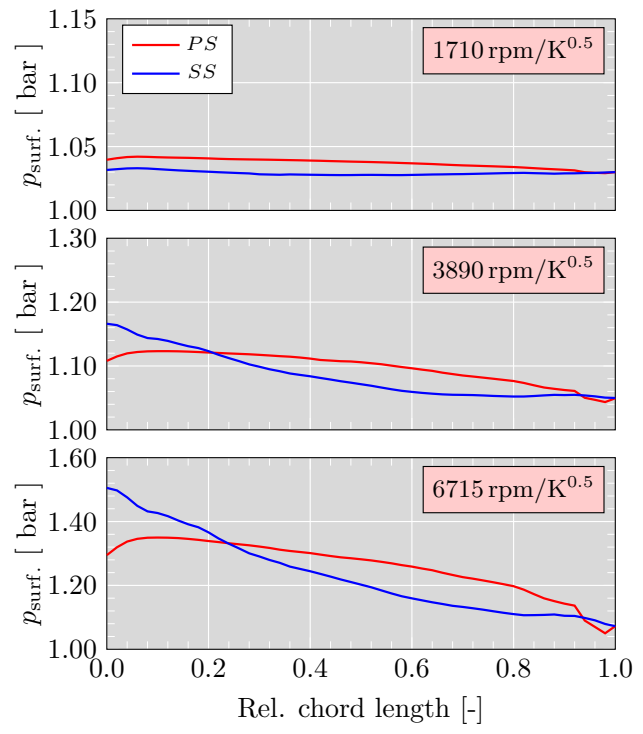

Figure 8: Surface pressure profiles at $95 \%$ span at lowest simulated $\pi_{\text {turb. }}$ for each speed with $60 \%$ VGT opening $\left(\pi_{\text {turb. }}: 1.03\right.$ at $1710 \mathrm{rpm} / \mathrm{K}^{0.5}, 1.10$ at $3890 \mathrm{rpm} / \mathrm{K}^{0.5}, 1.35$ at $\left.6715 \mathrm{rpm} / \mathrm{K}^{0.5}\right)$. 


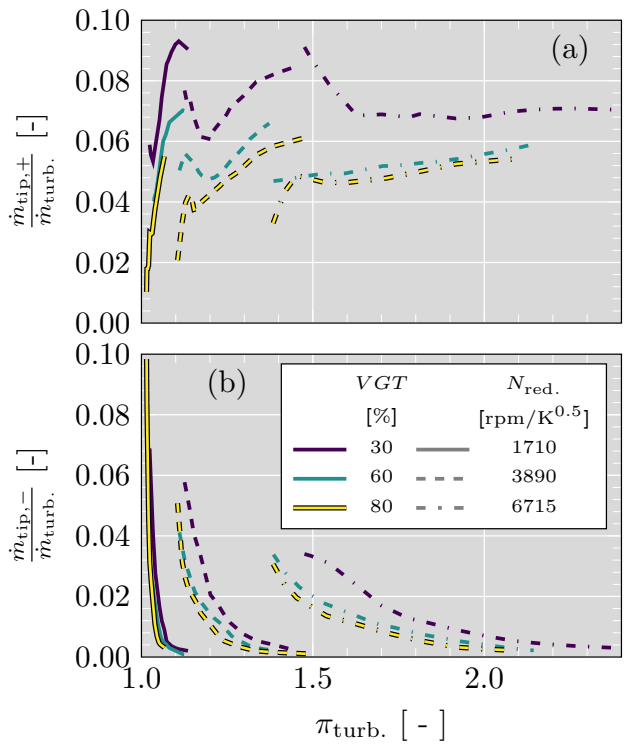

Figure 9: Relative tip leakage mass flow fraction: (a) flowing to blade SS; (b) flowing to blade PS.

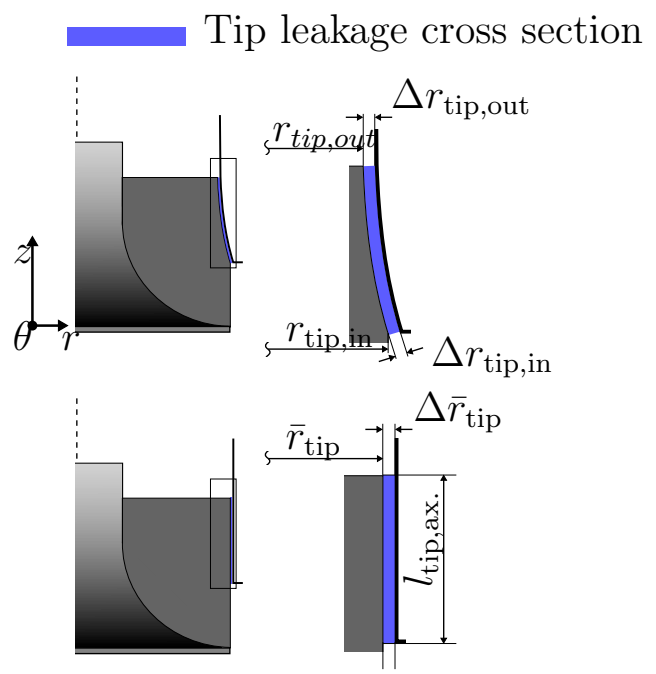

Figure 10: Geometry simplification of rotor tip gap. 


\section{Tip Leakage Loss \& Mass Flow Calculation}

To allow the modeling of wide range data, the new model has to consider effects which are dominant at low mass flows rates and effects of high dominance at higher mass flow rates. Especially for map extrapolation purposes, it is important to model both conditions as well as a transition phase in good quality. Here, data are usually fitted by means of measurements close to the optimum efficiency point and are extrapolated towards map regions of lower pressure ratio and mass flow. The portion of the total tip leakage mass flow (Equation 3) rises towards very low turbine mass flow and contributes significantly to the loss system. Thus, the new model has been derived from the Navier Stokes Equation in a cylindric rotating reference frame relying on geometrical simplifications which are later fit by a geometrical coefficient. The main geometrical assumption which allows most of the following aerodynamic simplifications is shown in Figure 10.

Since most tip gaps in radial or mixed flow turbocharger turbines have a rather low variation in radial direction, the clearance has been simplified to a tip gap with constant radii. The values $\bar{r}_{\text {tip }}$ and $\Delta \bar{r}_{\text {tip }}$ can be calculated as:

$$
\begin{gathered}
\bar{r}_{\text {tip }}=\frac{r_{\text {tip }, \text { out }}+r_{\text {tip }, \text { in }}}{2}, \\
\Delta \bar{r}_{\text {tip }}=\frac{\Delta r_{\text {tip }, \text { out }}+\Delta r_{\text {tip }, \text { in }}}{2}, \\
\bar{r}_{\text {sh. }}=\bar{r}_{\text {tip }}+\Delta \bar{r}_{\text {tip }} .
\end{gathered}
$$

It has been tested that the later model results change negligibly by changing $\bar{r}_{\text {tip }}$. Changes in $\Delta \bar{r}_{\text {tip }}$ influence the results severely but can be corrected by the proposed geometric coefficients.

\subsection{Loss Correlation}

First, the commonly used loss correlation for the tip leakage flow in Equation 7 has been modified to make it dependent of measured data.

$$
\Delta h_{\text {tip }, \text { loss }}=K \cdot \frac{\dot{m}_{\text {tip }}}{\dot{m}_{\text {turb. }}} \cdot \frac{w_{\text {tip }}^{2}}{2} \cdot z
$$

For simplicity the $\theta$-component of the tip leakage velocity has been used in the following. Transforming the mass flow fraction of Equation 7 to an expression including the reduced mass flow leads to: 


$$
\frac{\dot{m}_{\mathrm{tip}}}{\dot{m}_{\mathrm{turb} .}}=\frac{A_{\mathrm{tip}}}{\dot{m}_{\text {red.,turb. }}} \cdot \frac{w_{\mathrm{tip}, \theta}}{\sqrt{T_{\mathrm{t}, 0}}} \cdot \frac{T_{\mathrm{t}, 0}}{T_{\mathrm{tip}}} \cdot \frac{p_{\mathrm{tip}}}{p_{\mathrm{t}, 0}} \cdot \frac{\sqrt{c_{p}}}{\sqrt{c_{p}}} \cdot \frac{1}{R} .
$$

Instead of calculating the pressure $p_{\text {tip }}$ at several chord lengths of the tip gap, the outlet condition has been taken. For high temperatures it can be assumed that $\frac{T_{\mathrm{t}, \mathrm{tip}}}{T_{\text {tip }}}$ is close to 1 . Combining this assumption with the aspect of negligible work generation of the tip leakage flow, the ratio $\frac{T_{\mathrm{t}, 0}}{T_{\mathrm{tip}}}$ can be neglected leading to:

$$
\frac{\dot{m}_{\text {tip }}}{\dot{m}_{\text {turb. }}}=\frac{A_{\text {tip }}}{\dot{m}_{\text {red.,turb. }}} \cdot \frac{1}{\pi_{\text {turb. }}} \cdot \frac{w_{\text {tip }, \theta}}{\sqrt{c_{p} \cdot T_{\mathrm{t}, 0}}} \cdot \frac{\sqrt{c_{p}}}{R} .
$$

Thus, Equation 9 can be calculated by means of measurable data and the unknown $w_{\text {tip }, \theta}$. The non-dimensional formulation of $\frac{w_{\mathrm{tip}, \theta}}{\sqrt{c_{p} \cdot T_{\mathrm{t}, 0}}}$ can be substituted with a correlation including the Laval number:

$$
\frac{w_{\mathrm{tip}, \theta}}{\sqrt{c_{p} \cdot T_{\mathrm{t}, 0}}}=L a_{\mathrm{tip}} \cdot \sqrt{2} \cdot \sqrt{\frac{\gamma-1}{\gamma+1}} .
$$

\subsection{Tip leakage velocity modeling}

The simplification of the tangential velocity as the mass flow relevant (area orthogonal) velocity implies a geometrical simplification towards a flat and straight blade close to the tip. This might neglect the centrifugal forces on a fluid particle streamline, when the rotor passage is bent. However, this reduction of complexity allows to use only the $\theta$-component of the incompressible Navier Stokes Equation in a rotating cylindrical coordinate frame to calculate the required velocity:

$$
\begin{aligned}
& \rho\left(\frac{\partial w_{\theta}}{\partial t}+w_{r} \frac{\partial w_{\theta}}{\partial r}+\frac{w_{\theta}}{r} \frac{\partial w_{\theta}}{\partial \theta}+\frac{w_{r} w_{\theta}}{r}+w_{z} \frac{\partial w_{\theta}}{\partial z}\right) \\
= & -\frac{1}{r} \frac{\partial p}{\partial \theta}+\rho g_{\theta}-2 \rho \omega w_{r}+ \\
+ & \mu\left[\frac{1}{r} \frac{\partial}{\partial r}\left(r \frac{\partial w_{\theta}}{\partial r}\right)-\frac{w_{\theta}}{r^{2}}+\frac{1}{r^{2}} \frac{\partial^{2} w_{\theta}}{\partial \theta^{2}}+\frac{2}{r^{2}} \frac{\partial w_{r}}{\partial \theta}+\frac{\partial^{2} w_{\theta}}{\partial z^{2}}\right] .
\end{aligned}
$$

This strategy matches the observation done by Yaras et al. [28], that the cord wise momentum in a tip gap is nearly conserved. Starting from 
Equation 11 the following assumptions can be made maintaining the idea of a flat and straight blade close to the tip:

$$
\frac{\partial}{\partial t}, \frac{\partial}{\partial \theta}, \frac{\partial}{\partial z}, w_{r}=0
$$

Here, a stationary profile is assumed, which remains constant over the tip gap in z direction. According to Dambach and Hodson [29] and the tip flow analysis in this paper, inducer and exducer tip region have rather different leakage flow patterns. Thus, the aforementioned assumption might only be valid in different zones along the chord. However, the tip gap of radial or mixed flow turbocharger turbines feature rather radial gaps over the whole chord length. Hence, the Coriolis force has been neglected here. It has been assumed that the velocity profile does not change significantly in the tangential direction and does not own a radial component. Also the influence of gravity has been considered as negligible.

$$
\begin{gathered}
0=-\frac{1}{r} \frac{\partial p_{(\mathrm{PS}, \mathrm{SS})}}{\partial \theta}+\mu\left[\frac{1}{r} \frac{\partial}{\partial r}\left(r \frac{\partial w_{\mathrm{tip}, \theta}}{\partial r}\right)-\frac{w_{\mathrm{tip}, \theta}}{r^{2}}\right] \\
\int \frac{1}{\mu} \frac{\partial p_{(\mathrm{PS}, \mathrm{SS})}}{\partial \theta} \mathrm{d} r=r \frac{\partial w_{\mathrm{tip}, \theta}}{\partial r}-\int \frac{w_{\mathrm{tip}, \theta}}{r} \mathrm{~d} r
\end{gathered}
$$

To achieve an easily integrable function, the following substitutions are considered:

$$
\begin{gathered}
g=\frac{w_{\mathrm{tip}, \theta}}{r} \\
\frac{\partial g}{\partial r}=\frac{\partial w_{\mathrm{tip}, \theta}}{\partial r} \frac{1}{r}-\frac{w_{\mathrm{tip}, \theta}}{r^{2}} \\
r \frac{\partial g}{\partial r}+g=\frac{\partial w_{\mathrm{tip}, \theta}}{\partial r}
\end{gathered}
$$

By substituting Equation 15 and Equation 17 in Equation 14 the following equation has been obtained:

$$
\int \frac{1}{\mu} \frac{\partial p_{(\mathrm{PS}, \mathrm{SS})}}{\partial \theta} \mathrm{d} r=r^{2} \frac{\partial g}{\partial r}+r g-\int g \mathrm{~d} r .
$$

By further substituting Equation 19 in Equation 18 a homogeneous differential equation with non-constant coefficients appears, which can be solved easily. 


$$
\begin{gathered}
g=\frac{\partial f}{\partial r}, \\
\frac{1}{r^{2}} \int \frac{1}{\mu} \frac{\partial p_{(\mathrm{PS}, \mathrm{SS})}}{\partial \theta} \mathrm{d} r=\frac{\partial^{2} f}{\partial r^{2}}+\frac{1}{r} \frac{\partial f}{\partial r}-\frac{1}{r^{2}} f .
\end{gathered}
$$

After solving Equation 20 a simple function with two integration constants $C_{1}$ and $C_{2}$ has been obtained:

$$
f=C_{1} r+C_{2} \frac{1}{r}+\frac{r}{2} \frac{1}{\mu} \frac{\partial p_{(\mathrm{PS}, \mathrm{SS})}}{\partial \theta} \ln (r)-\frac{r}{4} \frac{1}{\mu} \frac{\partial p_{(\mathrm{PS}, \mathrm{SS})}}{\partial \theta} .
$$

Undoing the substitutions from $g$ to $w_{\text {tip }, \theta}$ and finding the integration constants by means of the known values $w_{\text {tip }, \theta}\left(\bar{r}_{\text {tip }}\right)=0$ and $w_{\text {tip }, \theta}\left(\bar{r}_{\text {sh. }}\right)=$ $\omega \cdot \bar{r}_{\text {sh. }}$ an equation for the velocity profile has been found:

$$
\begin{aligned}
w_{\text {tip }, \theta}(r)= & \frac{\left(\frac{r}{\bar{r}_{\text {tip }}^{2}}-\frac{1}{r}\right)}{\left(\frac{\bar{r}_{\text {sh. }}}{\bar{r}_{\text {tip }}^{2}}-\frac{1}{\bar{r}_{\text {sh. }}}\right)} \cdot \\
& \cdot\left[\omega \cdot \bar{r}_{\text {sh. }}-\frac{1}{2} \frac{1}{\mu} \frac{\partial p_{(\mathrm{PS}, \mathrm{SS})}}{\partial \theta} \bar{r}_{\text {sh. }} \ln \left(\frac{\bar{r}_{\text {sh. }}}{\bar{r}_{\text {tip }}}\right)\right]+ \\
& +r \ln \left(\frac{r}{\bar{r}_{\text {tip }}}\right) \cdot \frac{1}{2} \frac{1}{\mu} \frac{\partial p_{(\mathrm{PS}, \mathrm{SS})}}{\partial \theta} .
\end{aligned}
$$

According to Equation 22, $w_{\operatorname{tip}, \theta}$ depends on the pressure gradient in $\theta$ direction as well as on the rotational speed. Here, the pressure gradient can be understood as the pressure difference between suction side and pressure side. For further modeling purposes Equation 22 has been integrated:

$$
\begin{aligned}
& \int_{r_{i n}}^{r_{\text {out }}} w_{\text {tip }, \theta}(r) \mathrm{d} r=\frac{\left[\frac{\bar{r}_{\text {sh. }}^{2}-\bar{r}_{\text {tip }}^{2}}{2 \cdot \bar{r}_{\text {tip }}^{2}}+\ln \left(\frac{\bar{r}_{\text {tip }}}{\bar{r}_{\text {sh. }}}\right)\right]}{\left(\frac{\bar{r}_{\text {sh. }}}{\bar{r}_{\text {tip }}}-\frac{1}{\bar{r}_{\text {sh. }}}\right)} . \\
\cdot & {\left[\omega \cdot \bar{r}_{\text {sh. }}-\frac{1}{2} \frac{1}{\mu} \frac{\Delta p_{(\mathrm{PS}, \mathrm{SS})}}{\Delta \theta} \bar{r}_{\text {sh. }} \ln \left(\frac{\bar{r}_{\text {sh. }}}{\bar{r}_{\text {tip }}}\right)\right]+} \\
+ & {\left[\frac{\bar{r}_{\text {tip }}^{2}-\bar{r}_{\text {sh. }}^{2}}{4}+\frac{\bar{r}_{\text {sh. }}^{2}}{2} \cdot \ln \left(\frac{\bar{r}_{\text {sh. }}}{\bar{r}_{\text {tip }}}\right)\right] \cdot \frac{1}{2} \frac{1}{\mu} \frac{\Delta p_{(\mathrm{PS}, \mathrm{SS})}}{\Delta \theta} }
\end{aligned}
$$




\subsection{Pressure gradient modeling}

According to Yaras and Sjolander [17] the tip leakage flow pressure gradient depends mainly on the pressure difference between SS and PS in the main passage. Thus, a simple assumption can be made using two different power equations to achieve an estimation for a mean pressure loading from measured power, which lives up to the needs of one-dimensional modeling:

$$
\dot{W}=\Delta p_{(\mathrm{PS}, \mathrm{SS})} \cdot A_{\mathrm{bl} .} \cdot \omega \cdot \bar{r}=\frac{\Delta h_{t} \cdot \dot{m}_{\mathrm{ch}}}{z} .
$$

On the basis of Equation 24, relevant map information is included:

$$
\frac{\Delta p_{(\mathrm{PS}, \mathrm{SS})}}{p_{\mathrm{t}, 0}} \cdot A_{\mathrm{bl} .} \cdot \omega \cdot \bar{r}=\frac{\Delta h_{t}}{h_{\mathrm{t}, 0}} \frac{\dot{m}_{\mathrm{ch} .}}{z} \frac{c_{p} \cdot T_{\mathrm{t}, 0}}{p_{\mathrm{t}, 0}} .
$$

Finally, the following equation has been obtained to calculate the needed pressure difference of Equation 23 in $\theta$ direction:

$$
\Delta p_{(\mathrm{PS}, \mathrm{SS})}=\frac{\Delta h_{t}}{h_{\mathrm{t}, 0}} \frac{\dot{m}_{\text {red.,turb. }} \cdot c_{p} \cdot \sqrt{T_{\mathrm{t}, 0}} \cdot \pi_{\text {turb. }} \cdot p_{\text {out }}}{z \cdot A_{\mathrm{bl} .} \cdot \omega \cdot \bar{r}} .
$$

Here the inlet pressure $p_{\mathrm{t}, 0}$ has been substituted by $\pi_{\text {turb. }} \cdot p_{\text {out }}$ because $p_{\text {out }}$ is a rather constant value than the turbine inlet pressure during typical turbine map measurements. This way atmospheric pressure can be assumed as $p_{\text {out }}$ and variations from this value can be recovered by the geometric fitting coefficient. Further, model results have been improved by using the square root of $\pi_{\text {turb. }}$ :

$$
\Delta p_{(\mathrm{PS}, \mathrm{SS})}=\frac{\Delta h_{t}}{h_{\mathrm{t}, 0}} \frac{\dot{m}_{\text {red.,turb. }} \cdot c_{p} \cdot \sqrt{T_{\mathrm{t}, 0}} \cdot \sqrt{\pi_{\mathrm{turb}}} \cdot p_{\text {out }}}{z \cdot A_{\mathrm{bl} .} \cdot \omega \cdot \bar{r}} .
$$

\subsection{Modeling of contrariwise mass flow over the tip}

The possibly roughest simplification, that has been made, is to assume that no gradients in z-direction (axial direction) exist. As stated in this paper, even in radial turbocharger turbines with rather negligible axial tip gap, zones of dominating negative and dominating positive tip leakage flow exist. This leads to the simple modeling of two flows where either the effect of rotational speed or the effect of blade loading can be neglected in Equation 23. Following the velocity and mass flow of two zones can be calculated separately to formulate the tip leakage loss 


$$
\begin{aligned}
\frac{\dot{m}_{\text {tip },+}}{\dot{m}_{\text {turb. }}}= & \frac{A_{\text {tip }}}{\dot{m}_{\text {red.,turb. }}} \cdot \frac{L a_{\text {tip },+}}{\pi_{\text {turb. }}} . \\
& \cdot \sqrt{\frac{\gamma-1}{\gamma+1}} \cdot \frac{\sqrt{2 \cdot c_{p}}}{R \cdot \cos \left(\beta_{\text {rot.,in }}-\beta_{\text {opt.,in }}\right)}, \\
\frac{\dot{m}_{\text {tip },-}}{\dot{m}_{\text {turb. }}}= & \frac{A_{\text {tip }}}{m_{\text {red.,turb. }}} \cdot \frac{L a_{\text {tip },-}}{\pi_{\text {turb. }}} \cdot \sqrt{\frac{\gamma-1}{\gamma+1}} \cdot \frac{\sqrt{2 \cdot c_{p}}}{R} .
\end{aligned}
$$

Equation 28 for positive mass flow has been configured according to Yaras and Sjolander [30], who related the blade loading with $\cos \beta_{\text {rot,in }}$ and the tip leakage. Passing the tip leakage at the inlet zone of the rotor $p_{\text {tip }}$ of Equation 8 is higher for the negative tip leakage flow. This has been taken into account by using the square root of the turbine expansion ratio $\pi_{\text {turb. }}$. If a full turbine one dimensional model supplies the pressure ratio of total inlet pressure $p_{\mathrm{t}, 0}$ to static rotor inlet pressure $p_{\text {rot,in }}$, this ratio can be used instead.

The velocities for positive and negative Laval numbers have been modeled from the integral over the full tip clearance (Equation 23) divided by the tip gap height $\Delta \bar{r}_{\text {tip }}$. The effects of wall friction and pressure gradient have been separated and assigned to negative and positive tip clearance velocity components as follows:

$$
\begin{aligned}
& \left.w_{\text {tip }, \theta,+}=\frac{\left[\frac{\bar{r}_{\text {sh. }}^{2}-\bar{r}_{\text {tip }}^{2}}{2 \cdot \bar{r}_{\text {tip }}^{2}}+\ln \left(\frac{\bar{r}_{\text {tip }}}{\bar{r}_{\text {sh. }}}\right)\right]}{\left(\bar{r}_{\text {sh. }}\right.}-\frac{1}{\bar{r}_{\text {tip }}^{2}}\right) \\
& \cdot\left[-\frac{1}{2} \frac{1}{\mu} \frac{\Delta p_{(\mathrm{PS}, \mathrm{SS})}}{\Delta \theta \Delta \bar{r}_{\text {tip }}} \bar{r}_{\text {sh. }} \cdot \ln \left(\frac{\bar{r}_{\text {sh. }}}{\bar{r}_{\text {tip }}}\right)\right]+ \\
& +\left[\frac{\bar{r}_{\text {tip }}^{2}-\bar{r}_{\text {sh. }}^{2}}{4}+\frac{\bar{r}_{\text {sh. }}^{2}}{2} \cdot \ln \left(\frac{\bar{r}_{\text {sh. }}}{\bar{r}_{\text {tip }}}\right)\right] . \\
& \cdot \frac{1}{2} \frac{1}{\mu} \frac{\Delta p_{(\mathrm{PS}, \mathrm{SS})}}{\Delta \theta \Delta \bar{r}_{\text {tip }}},
\end{aligned}
$$


Since the most radical simplification have been assumed to simplify the Navier Stokes Equation and to obtain the velocity component $w_{\text {tip }, \theta}$, two fitting coefficients $K_{+}$and $K_{-}$have been introduced into the final velocity equations for positive and negative tip velocity. $K_{+}$reduces the tip gap height to an effective section. Thus, the initial loss coefficient $K$ in Equation 7 is redundant and can be left out.

Formulating Equation 7 as a loss relative to the inlet enthalpy, substituting Equation 9 and Equation 10 the overall relative tip loss can be calculated as:

$$
\begin{aligned}
\frac{\Delta h_{\mathrm{tip}, \text { loss }}}{h_{\mathrm{t}, 0}} & =\frac{\dot{m}_{\mathrm{tip},+}}{\dot{m}_{\mathrm{turb}} .} \cdot \frac{\gamma-1}{\gamma+1} \cdot L a_{\mathrm{tip},+}^{2} \cdot z+ \\
& +\frac{\dot{m}_{\mathrm{tip},-}}{\dot{m}_{\mathrm{turb} .}} \cdot \frac{\gamma-1}{\gamma+1} \cdot L a_{\mathrm{tip},-}^{2} \cdot z
\end{aligned}
$$

and its effect on the turbine efficiency as:

$$
\eta_{\mathrm{t}, \mathrm{s}}=\frac{\Delta h_{\mathrm{t}}}{h_{\mathrm{t}, 0}} \cdot\left[1-\left(\frac{1}{\pi_{\text {turb. }}}\right)^{\frac{\gamma-1}{\gamma}}\right]^{-1}-\Delta \eta_{\text {tip }, \text { loss }},
$$

and with $\Delta \eta_{\text {tip,loss }}$ as:

$$
\Delta \eta_{\mathrm{tip}, \text { loss }}=\frac{\Delta h_{\mathrm{tip}, \text { loss }}}{h_{\mathrm{t}, 0}} \cdot\left[1-\left(\frac{1}{\pi_{\text {turb. }}}\right)^{\frac{\gamma-1}{\gamma}}\right]^{-1} .
$$

It can be seen that apart from map data, gas data, and geometrical data only the relative rotor inflow angle $\beta_{\text {rot,in }}$ is needed. In common one dimensional models this angle is typically calculated. Hence, no additional effort has to be done to use the presented model.

\section{Model validation \& Discussion}

To prove the validity of the model the relative leakage mass flow as well as the tip leakage loss, according to Equation 7, have been validated by means of the CFD data. 


\subsection{Loss modeling}

First, the tip leakage efficiency model has been fitted with all available data from calculated simulations at the same time using the estimated loss according to Equation 34. Here, simulated data has been chosen as input to allow a consistent comparison between model and CFD results. As fitting coefficients 0.1824 and 0.4848 have been obtained for $K_{+}$and $K_{-}$accordingly. The low magnitude of $K_{+}$can be explained by the effective tip gap reduction due to flow separation, blocking, the dragging flow, mixing zones, and discharged flow (Dambach and Hodson [29]). Inherent in the coefficients $K_{+}$and $K_{-}$is a correction of the chordwise extension of the flow into the related direction. This also explains the magnitude of $K_{-}$.

The results in Figure 11 show the flexibility of the developed model to fit the whole data range. It can be seen that the overall fitting quality is good. However, the efficiency loss fitting is rather bad for the points of highest $\pi_{\text {turb. }}$ with the speed of $1710 \mathrm{rpm} / \mathrm{K}^{0.5}$. In this region the model under predicts the efficiency loss. At the speed of $6715 \mathrm{rpm} / \mathrm{K}^{0.5}$ and with $60 \%$ and $80 \%$ VGT opening the model also under predicts the estimated efficiency loss at lower pressure ratios and slightly over predicts the loss at higher pressure ratios. Looking at the relative rotor inlet flow angle $\beta_{\text {rot,in }}$ of simulation results in Figure 6, it becomes clear that the tip leakage loss fitting is worse for points with a positive or close to zero inflow angle. During the development of the model significant modeling improvements have already been obtained for these points by using the aforementioned correlation with $\cos \beta_{\text {rot., in }}$ (Equation 28). However the error in tip leakage efficiency loss remains rather high in this points, the absolute error in turbine power loss is rather low compared with other impacting factors as heat transfer or measurement uncertainties especially at this speed where the power output is rather low as it can be seen in Figure 2. In general, a good fitting has been achieved for three VGT positions, three speeds spreading a wide range, and pressure ratios between 1.015 and 2.5 with only two fitting coefficients. Thus, the trends of all variable impact factors on the variable geometry turbine are correctly modeled.

Since the model is supposed to be used in a narrow map extrapolation model, its extrapolation capability has to be validated. In commonly available turbocharger turbine maps rather low number of measured points are available at only high expansion ratios.

Thus, for validating the functionality of the tip clearance model regarding its extrapolation capability five points (with highest expansion ratios) of 

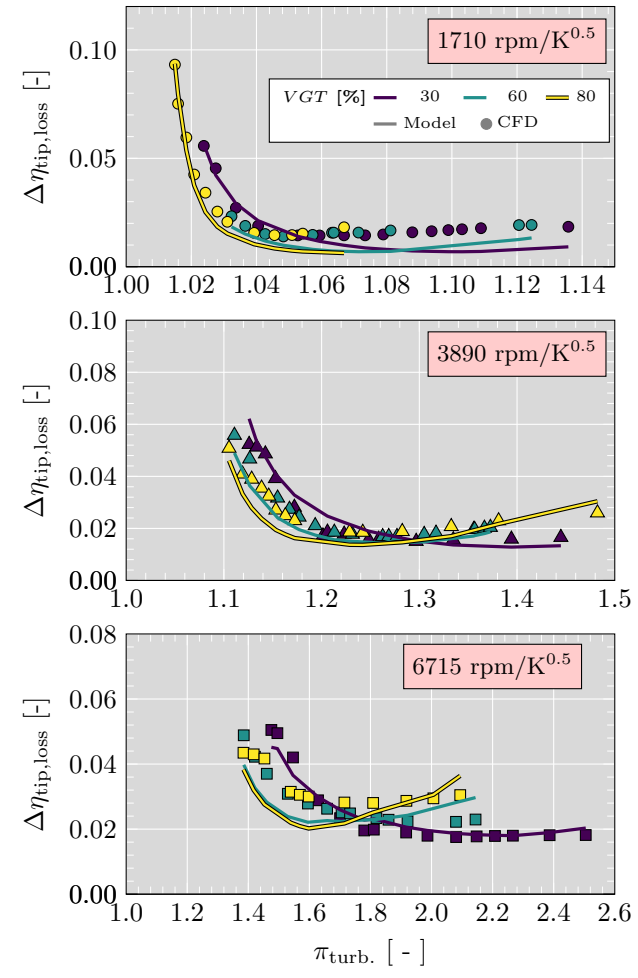

Figure 11: Efficiency model fitting for single speeds vs. $\pi_{t u r b .}$. 

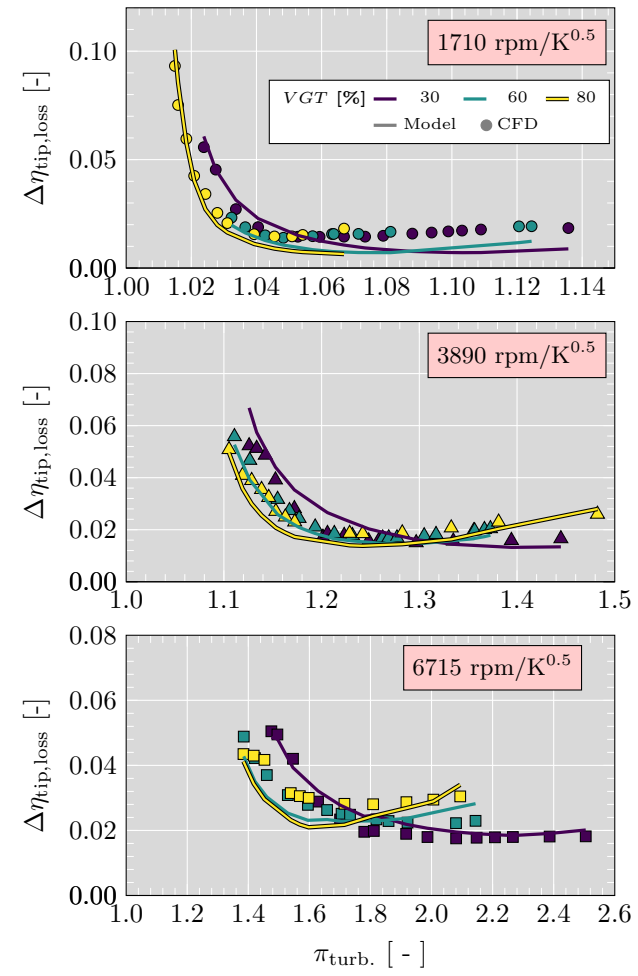

Figure 12: Model extrapolation of tip loss related efficiency vs. $\pi_{t u r b}$. and after fitting $K_{+}$ and $K_{-}$coefficients with only five points at the highest $\pi_{t u r b}$. for each speedline (independent of VGT opening).

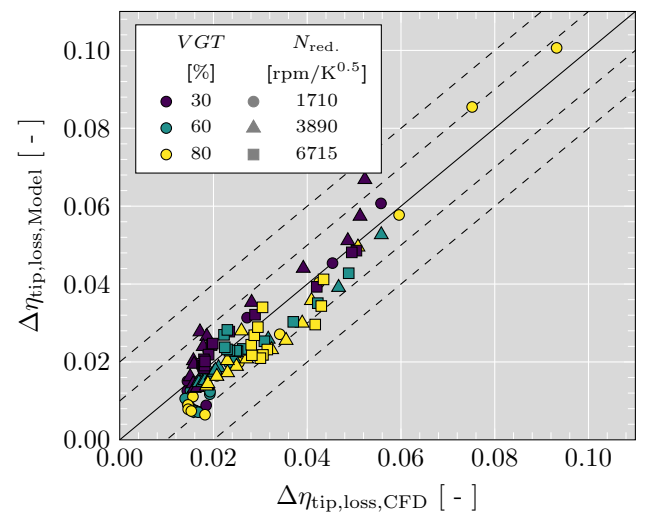

Figure 13: Model extrapolation of tip loss related efficiency vs. CFD results and after fitting $K_{+}$and $K_{-}$coefficients with only five points at the highest $\pi_{t u r b}$. for each speedline (independent of VGT opening). 
every speedline and VGT opening have been used to fit the model with the same coefficients. As common $K_{+}$and $K_{-}$have been fitted to 0.1803 and 0.4966. By following this strategy, the fitting coefficients and the model results in Figure 12 are almost identical to the case where all data have been used for the data fitting (Figure 11). Like in the whole data fitting, the fitting at design conditions at $1710 \mathrm{rpm} / \mathrm{K}^{0.5}$ is of lower quality. The efficiency loss is extrapolated towards low pressure ratios in very high quality as it can be seen in Figure 12 and Figure 13. This highlights the high consistency and stability of the model. The fitting and extrapolating errors are lower than 1 percentage point for $94.3 \%$ of the points as shown by Figure 13. The relative root mean square error (RMSE) is $16.3 \%$. Although highest relative errors have been obtained at $1710 \mathrm{rpm} / \mathrm{K}^{0.5}$ around operating points that have been used for the model fitting, the extrapolation quality is not negatively affected.

\subsection{Mass flow modeling}

Since the tip leakage mass flow can be a valuable information for one dimensional models, the tip leakage mass flow fraction calculated with the found coefficients of the tip leakage loss fitting is shown in Figure 14.

At $1710 \mathrm{rpm} / \mathrm{K}^{0.5}$ and higher pressure ratios the model mass flow fraction shows rather poor agreement with the CFD data due to the aforementioned reasons. However, the tip leakage mass flow fraction at extremely low pressure ratios is well estimated by the model. For all points of $3890 \mathrm{rpm} / \mathrm{K}^{0.5}$ and for the most points of $6715 \mathrm{rpm} / \mathrm{K}^{0.5}$ a very good agreement has been achieved. The overall model trends are good estimated (as it can be seen in Figure 15), although a dedicated tuning of the fitting parameters on the basis of the mass flow fraction data has not been carried out. A relative RMSE of $11.7 \%$ has been calculated.

\section{Conclusion \& Future Work}

Steady CFD simulations of a turbocharger radial turbine have shown that up to $14 \%$ of the mass flow can pass through the rotor clearance at off-design conditions. Depending on the VGT position the mass flow ratio ranges from $5 \%$ to almost $10 \%$ at design condition.

Different causing effects are dominating at certain running conditions. While the leakage mass flow driven by the pressure gradient between suction and pressure surface dominates at design conditions, shroud friction and high incidence effects provoke contrariwise leakage mass flow at off-design 

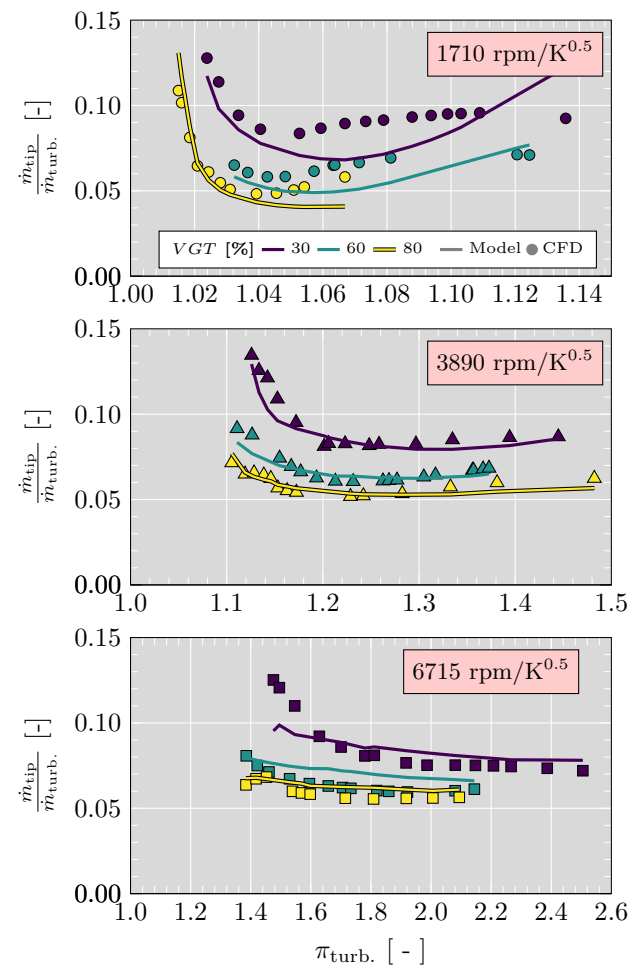

Figure 14: Model mass flow ratio extrapolation vs. $\pi_{t u r b}$. and after fitting $K_{+}$and $K_{-}$ coefficients with only five points at the highest $\pi_{t u r b}$. for each speedline (independent of VGT opening).

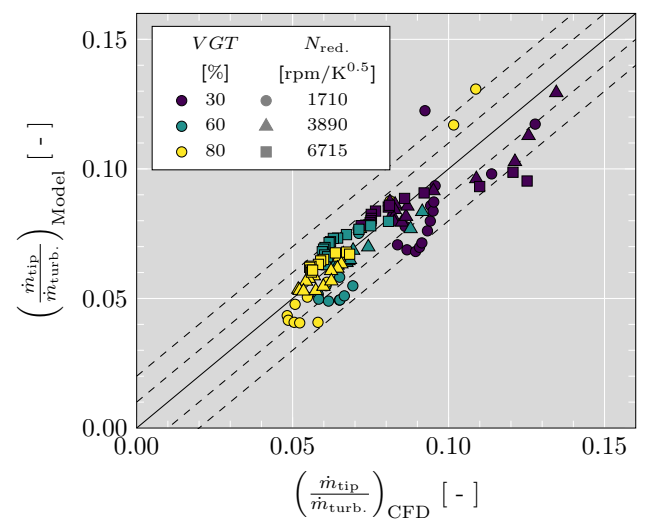

Figure 15: Model mass flow ratio extrapolation vs. CFD results and after fitting $K_{+}$and $K_{-}$coefficients with only five points at the highest $\pi_{t u r b}$. for each speedline (independent of VGT opening). 
conditions. The contrariwise leakage due to shroud friction can be neglected in design points but dominates the tip clearance in the rotor inlet section when operating in extreme off-design conditions.

Backflow close to the hub of the rotor can restrict the rotor effective area and increases the blade loading close to the rotor tip while the turbine pressure ratio becomes lower. This increases the pressure gradient driven mass flow after a decrease due to reducing blade loading.

The modeling of dragging and loading effects are important to realize good quality extrapolations based on design point data. The developed model is able to fit and extrapolate the CFD data in a wide range using mainly map data, gas data, and simple geometrical data. Fitting the tip leakage losses, also the mass flow fraction has been calculated in a good quality compared to CFD data.

Since the model has a strict physical basis, future analysis of further turbine geometries might make it possible to relate the two introduced fitting coefficients. Also, a prediction of tip clearance losses and mass flow without fitting (just dependent on geometrical data) can be addressed due to the geometric dependence of the model.

\section{Acknowledgements}

The work has been partially supported by FEDER and the Spanish Ministry of Economy and Competitiveness through grant number TRA201679185-R.

\section{Nomenclature}

$\begin{array}{lll}A & \text { Area } & \mathrm{m}^{2} \\ c_{p} & \text { Isobaric specific heat capacity } & \mathrm{J} \mathrm{kg}^{-1} \mathrm{~K}^{-1} \\ f & \text { Substitution value } & - \\ g & \text { Substitution value } & - \\ g_{\theta} & \text { Gravity vector component } & \mathrm{m} \mathrm{s}^{-2} \\ h & \text { Enthalpy } & \mathrm{J} \mathrm{kg}^{-1} \\ K & \text { Fitting constant } & - \\ \dot{m} & \text { Mass flow } & \mathrm{kg} \mathrm{s}^{-1} \\ N & \text { Rotational speed } & \mathrm{rpm}^{2}\end{array}$




$\begin{array}{lll}p & \text { Pressure } & \mathrm{Pa} \\ \mathrm{PS} & \text { Pressure Side } & - \\ R & \text { Specific gas constant } & \mathrm{J} \mathrm{kg}^{-1} \mathrm{~K}^{-1} \\ r & \text { Radius } & \mathrm{m} \\ \mathrm{SS} & \text { Suction Side } & - \\ T & \text { Temperature } & \mathrm{K} \\ \text { VGT } & \text { Variable Geometry Turbine } & - \\ W & \text { Power } & \mathrm{W} \\ w & \text { Velocity in relative reference frame } & \mathrm{m} \mathrm{s}^{-1} \\ z & \text { Blade number } & - \\ & & \\ \text { Greek } & \text { letters } & \\ \beta & \text { Angle in relative reference frame } & \circ \\ \gamma & \text { Heat capacity ratio } & - \\ \partial & \text { Differential } & - \\ \Delta & \text { Difference } & - \\ \eta & \text { Efficiency } & - \\ \theta & \text { Circumferential components } & - \\ \rho & \text { Density } & \mathrm{kg} \mathrm{m}^{-3} \\ \pi & \text { Corresponding pressure ratio } & - \\ \omega & \text { Angular velocity } & \mathrm{s}^{-1} \\ \mu & \text { Dynamic viscosity } & \mathrm{kg} \mathrm{s}^{-1} \mathrm{~m}^{-1} \\ & & \\ & & \\ \text { bl. } & \text { Blade parameter } & \\ \text { CFD } & \text { CFD data } & \\ \text { ch. } & \text { Channel } & \\ \text { exp. } & \text { Experimental data } & \\ \text { in } & \text { Turbine rotor inlet section } & \\ \text { out } & \text { Turbine rotor outlet section } & \\ \text { PS } & \text { Pressure Side } & \\ r & \text { Radial direction } & \\ \text { red. } & \text { Reduced numbers } & \\ \text { SS } & \text { Suction Side } & \\ & & \\ & \end{array}$


sh. Value at shroud

t Total or stagnation condition

tip Value at rotor tip

turb. Turbine

$z \quad$ Axial direction

Greek letters

$\theta \quad$ Circumferential components

Numbers \& Symbols

0 Turbine inlet section

Averaged value

$+\quad$ Positive mass flow direction identifier

- $\quad$ Negative mass flow direction identifier

$\perp \quad$ Perpendicular flow component

\section{References}

[1] Regulation (EC) No 715/2007 of the European Parliament and of the Council of 20 June 2007 on type approval of motor vehicles with respect to emissions from light passenger and commercial vehicles (Euro 5 and Euro 6) and on access to vehicle repair and maintenance information (Text with EEA relevance) . Official Journal of the European Union 2007;50:1-16. URL: http://eur-lex.europa.eu/legal-content/EN/ TXT/?uri=0J :L:2007:171: TOC.

[2] Galindo, J., Fajardo, P., Navarro, R., García-Cuevas, L.M.. Characterization of a radial turbocharger turbine in pulsating flow by means of CFD and its application to engine modeling. Applied Energy 2013;103:116-127. doi:10.1016/j . apenergy . 2012.09.013.

[3] Romagnoli, A., Martinez-Botas, R.. Performance prediction of a nozzled and nozzleless mixed-flow turbine in steady conditions. International Journal of Mechanical Sciences 2011;53(8):557 - 574.

[4] Bellis, V.D., Bozza, F., Schernus, C., Uhlmann, T.. Advanced numerical and experimental technique for the extension of turbine mapping. SAE int J Engines 2013;3(6):1771-1785. doi:10.4271/2013-24-0119. 
[5] Smiljanovski, V., Schorn, N., Scharf, J., Funken, B., Pischinger, S.. Messung des turbinenwirkungsgrades bei niedrigen turboladerdrehzahlen. Aufladetechnische Konferenz 2008;.

[6] Terdich, N.. Impact of electrically assisted turbocharging on the transient response of an off-highway diesel engine. Ph.D. thesis; Imperial College London; 2015.

[7] Salameh, G., Chesse, P., Chalet, D.. Different measurement techniques for wider small radial performance maps. Experimental Techniques 2016;40(6):1511-1525. doi:10.1007/s40799-016-0107-8.

[8] Serrano, J.R., Tiseira, A., García-Cuevas, L.M., Inhestern, L.B., Tartoussi, H.. Radial turbine performance measurement under extreme off-design conditions. Energy 2017;125:72 - 84. doi:10.1016/j . energy . 2017.02 .118$.

[9] Serrano, J.R., García-Cuevas, L.M., Inhestern, L.B., Mai, H., Rinaldi, A., Miguel-Sanchez, A.. Methodology to evaluate turbocharger turbine performance at high blade to jet speed ratio under quasi adiabatic conditions. GT2017-63360 Proceeding of the ASME 2017 Turbo Expo 26-30 June 2017 Charlotte,NC USA (accepted for publication) 2017;

[10] Payri, F., Serrano, J.R., Fajardo, P., Reyes-Belmonte, M.A., GozalboBelles, R.. A physically based methodology to extrapolate performance maps of radial turbines. Energy Conversion and Management 2012;55(0):149 - 163. doi:10.1016/j . enconman.2011.11.003.

[11] Zhu, S., Deng, K., Liu, S.. Modeling and extrapolating mass flow characteristics of a radial turbocharger turbine. Energy 2015;87:628637. doi:10.1016/j . energy.2015.05.032.

[12] Aymanns, R., Scharf, J., Uhlmann, T., Lückmann, D.. A revision of quasi steady modelling of turbocharger turbines in the simulation of pulse charged engines. In: 16th Supercharging Conference. 2011,.

[13] Serrano, J.R., Arnau, F.J., García-Cuevas, L.M., Dombrovsky, A., Tartousi, H.. Development and validation of a radial turbine efficiency model at extreme off-design conditions. Energy Conversion and Management 2016;doi:10.1016/j . enconman.2016.09.032. 
[14] Baines, N.. A meanline prediction method for radial turbine efficiency. In: IMECHE conference transactions; vol. 11. Mechanical Engineering Publications; 1998, p. 45-56.

[15] Dambach, R., Hodson, H., Huntsman, I.. An experimental study of tip clearance flow in a radial inflow turbine. In: ASME 1998 International Gas Turbine and Aeroengine Congress and Exhibition. American Society of Mechanical Engineers; 1998, p. V001T01A110-V001T01A110.

[16] Deng, Q., Niu, J., Feng, Z.. Study on leakage flow characteristics of radial inflow turbines at rotor tip clearance. Science in China Series E: Technological Sciences 2008;51(8):1125-1136. URL: http://dx.doi. org/10.1007/s11431-008-0164-z. doi:10.1007/s11431-008-0164-z.

[17] Yaras, M., Sjolander, S.. Prediction of tip-leakage losses in axial turbines. In: ASME 1990 International Gas Turbine and Aeroengine Congress and Exposition. American Society of Mechanical Engineers; 1990, p. V001T01A050-V001T01A050.

[18] Baines, N.. Radial turbine design. In: Axial and Radial Turbines. Concepts NREC; 2006,.

[19] Spraker, W.A.. Contour clearance losses in radial inflow turbines for turbochargers. ASME Paper 1987;(87-ICE-52).

[20] Wallace, F.. Theoretical assessment of the performance characteristics of inward radial flow turbines. Proceedings of The Institution of Mechanical Engineers 1958;172(1):931-952.

[21] Kammeyer, J., Natkaniec, C., Seume, J.R.. Tip leakage in small radial turbines: Optimum tip-gap and efficiency loss correlations. In: ASME Turbo Expo 2010: Power for Land, Sea, and Air. American Society of Mechanical Engineers; 2010, p. 391-401.

[22] Serrano, J.R., Gil, A., Navarro R. Inhestern, L.B.. Extremely low mass flow at high blade to jet speed ratio in variable geometry radial turbines and its influence on the flow pattern: a cfd analysis. GT2017-63368 Proceeding of the ASME 2017 Turbo Expo 26-30 June 2017 Charlotte,NC USA 2017; 
[23] Galindo, J., Tiseira, A., Navarro, R., López, M.. Influence of tip clearance on flow behavior and noise generation of centrifugal compressors in near-surge conditions. International Journal of Heat and Fluid Flow 2015;52:129-139. doi:10.1016/j . ijheatfluidflow. 2014.12.004.

[24] Menter, F.R.. Two-equation eddy-viscosity turbulence models for engineering applications. AIAA journal 1994;32(8):1598-1605.

[25] Menter, F.R., Langtry, R., Hansen, T.. CFD simulation of turbomachinery flowsverification, validation and modeling. In: European Congress on Computational Methods in Applied Sciences and Engineering, ECCOMAS. 2004,.

[26] Simpson, A.T., Spence, S.W.T., Watterson, J.K.. A comparison of the flow structures and losses within vaned and vaneless stators for radial turbines. Journal of Turbomachinery 2009;131.

[27] Galindo, J., Hoyas, S., Fajardo, P., Navarro, R.. Set-up analysis and Optimization of CFD Simulations for Radial Turbines. Engineering Applications of Computational Fluid Mechanics 2013;7(4):441-460. doi:10.1080/19942060.2013.11015484.

[28] Yaras, M., Zhu, Y., Sjolander, S.. Flow field in the tip gap of a planar cascade of turbine blades. Journal of Turbomachinery 1989;111(3):276283.

[29] Dambach, R., Hodson, H.. Tip leakage flow in a radial inflow turbine with varying gap height. Journal of Propulsion and Power 2001;17(3):644-650.

[30] Yaras, M., Sjolander, S.. Prediction of tip-leakage losses in axial turbines. ASME J Turbomach 1992;114(1):204-210. 